Field-dependent/independent cognitive style preferences of EFL learners in an implicit learning task from information processing perspective: A qualitative investigation

\author{
Hamed Mahvelati, Elaheh $\measuredangle$ \\ Abadan Faculty of Petroleum Engineering, Petroleum University of Technology, Iran (Mahvelati.e@ put.ac.ir)
}

Received: 6 October 2018

Available Online: 14 February 2019
Revised: 27 December 2018 DOI: $10.5861 /$ ijrsll 2019.3009

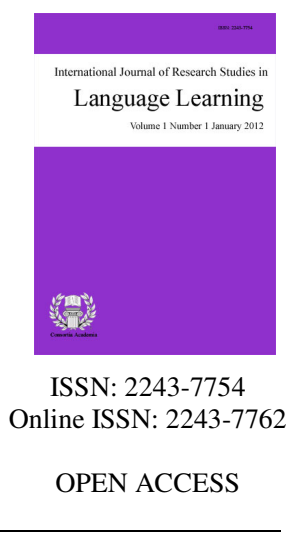

\title{
Abstract
}

Individuals' field-dependent/independent cognitive style is regarded as one of the most important factors affecting second language learning. However, there is a paucity of attention towards its significant role in instructional planning. This study aimed to find out how learners with different field-dependent and field-independent cognitive tendencies approach the task of learning through an implicit planned focus-on-form teaching method from information processing perspective. More precisely, it was attempted to find out if individual field-dependent/independent cognitive style differences affect the three stages of information processing (viz attention, perception/encoding and memory) and consequently the learning outcome. Three qualitative methods, namely retrospective-reflective tasks, tests of intake and interviews, were utilized to achieve this aim. This is while the majority of the studies in the related literature have been quantitative to date. Thirty four Iranian EFL field-dependent and field-independent learners at intermediate level participated in this study. The results revealed that the particular characteristics of the field-independent learners led to their superior performance in the attentional processes in the sensory-memory stage, the storage of information in working memory, and consequently the recall and retrieval processes of shortand long-term memory. Such finding suggests that field-independent learners are better input processors and therefore more successful in the tasks demanding autonomous and active analysis of the input. Furthermore, the sub-findings emerging from the results accentuated the significant impact of learners' field-dependent/independent cognitive style on the effectiveness of a teaching method in a learning setting. Some pedagogical implications are discussed.

Keywords: cognitive style of field-dependence; field-independent cognitive style; attentional processes; storage of information in working memory; recall and retrieval processes 


\section{Field-dependent/independent cognitive style preferences of EFL learners in an implicit learning task from information processing perspective: A qualitative investigation}

\section{Introduction}

A great number of researchers see individuals' cognitive style of field-dependence/independence (FD/FI) as one of the determining factors which affect the way learners perceive and respond to a learning task through a teaching method and therefore the degree to which they can benefit from that particular instructional approach (Angeli, 2013; Corno, 2008; Nozari \& Siamian, 2015; Rittschof, 2010; Tinajero, Castelo, Guisande, \& Páramo, 2011). FD/FI cognitive style refers to the individual learners' differences in the way they "attend to, recognize and structure perceptual patterns. They reflect the way pattern recognition is processed and retained in memory" (Pithers, 2002, p. 118). However, the claim of other researchers, such as Dyer and Observe (1996) and Griffiths and Sheen (1992), that the learners' FD/FI cognitive style does not affect the effectiveness of an instructional approach or learning outcomes has provoked an ongoing debate. In response to these arguments, some studies have been conducted to investigate the possible differences between FD and FI learners' quality of learning outcomes through various language teaching methods. Reviewing these studies identifies gaps in the current research and the need for this study to fill the gaps.

The literature review revealed the following:

$>\quad$ Most of these studies have compared the overall final performance score results of FD and FI learners. Only few studies have gone beyond the quantitative level and investigated the issue more deeply by employing qualitative research methods to throw light on the dark layers of learners' minds regarding the way they perceive and process the received information. Despite specialists' great emphases on the significance of studying information processing paradigms in gaining a clearer understanding of FD/FI leaning behavior (Davis \& Cochran, 1989; Messik, 1970), the majority of L2 studies in this body of research have not applied them to their research efforts. As a result, there is a dearth of empirical studies on FD and FI learners' mental experiences in each stage of information processing in different foreign/second language instructional designs. This necessitates conducting further studies employing qualitative research methods to clearly identify FD and FI learners' differences in information processing components and to provide compelling empirical evidence for the educational implications of FD/FI cognitive style.

$>\quad$ The learning performance of these two types of learners has been compared in different areas of second language (L2) learning, e.g. vocabulary by Niroomand and Rostampor (2014), reading by Ghonsooly and Eghtesadee (2006) and grammar by Abraham (1983). Nonetheless, no researcher, to the best of the present researcher's knowledge, has addressed this issue in the area of collocation (e.g. make an effort) which is widely believed to have a key role in language learning (Hoey, 2012; Laufer, \& Waldman, 2011; Lewis, 1993; Nesselhauf, 2003). Hill (2000), for example, contends that collocation is as important as 'other aspects of language such as pronunciation, intonation, stress, and grammar' (p. 59) and emphasizes that it has a crucial role in promoting recall and thinking in L2 acquisition and production. Similarly, Lewis (2000) highlights the importance of knowing collocational fields of words by asserting that this knowlege provides a basis for all language use. He, therefore, emphasizes that teachers should give main priority to teaching collocation in every language course' (p.8). Such great emphases on the importance of collocation knowledge development have led to the emergence of various pedagogical suggestions. A review of studies examining their effectiveness indicates that the researchers' almost exclusive focus has been on teaching/teacher related factors. They have, therefore, neglected the role of learners' individual FD/FI characteristics. This is while it is widely believed that this heuristic cognitive style construct has a significant role in 
Field-dependent/independent cognitive style preferences of EFL learners in an implicit learning task

the success or failure of an instructional method in bringing about the desired learning results. (Zahn $\&$ Sternberg, 2006). Such neglect is one of the likely reasons for the inconsistency of research findings in the area of collocation teaching.

None of these research studies has compared the learning performance and outcomes of FDs and FIs through input-flood treatment as one of the implicit planned focus-on-form teaching methods. This is while it is one of the most highly controversial teaching methods in the area of second language acquisition (SLA) (Hernández, 2011). In this implicit teaching technique, plentiful examples of a particular feature are presented in the instructional input in order to draw learners' attention to that feature without any explicit form of instruction or feedback (Ellis, 2001). The researchers who have examined the effectiveness of input-flood in the area of L2 teaching, in general, and collocation instruction, in particular, have reported mixed findings (e.g., Mirzapour \& Barjasteh, 2017; Öztina, 2009; Szudarski \& Carter 2016; White, 2008). A likely reason for the inconsistent results is that the role of learners' FD/FI cognitive tendencies as one of the factors contributing to the success or failure of this instructional approach was not taken into account. This is while it has been proved that optimum learning performance can only be achieved when an instructional method is aligned with the learners' particular characteristics such as FD/FI cognitive style (Tinajero et al., 2011). Given this, conducting more learner-focused research regarding the effectiveness of this teaching method is an absolute necessity.

Taking all these facts into consideration, the need for conducting a study which sheds light on how learners with different FD/FI cognitive characteristics attend to, perceive, process and retrieve collocations as the target features embedded in input is clearly evident. The current research, therefore, attempted to address this need by studying FD and FI learners' cognitive style preferences in the three stages of information processing (attention, encoding and memory) through the qualitative methods of retrospective-reflective tasks, tests of intake and in-depth interviews. The significance of this study lies in the fact that little research has used qualitative methods to achieve deeper insights into the way FDs and FIs approach a learning task in an instructional design. Indeed, the present study intended to make a contribution to the series of empirical studies examining the impact of learners' FD/FI cognitive style on the effectiveness of instructional approaches. Since the effect of these individual differences is believed to be more marked in the case of implicit learning tasks, input-flood, which is one of the highly contentious input-enhancement techniques, was selected as the research treatment. The study therefore contributes to the body of research investigating the influence of extensive exposure through input flood technique on L2 acquisition, in general, and collocation learning, in particular. Furthermore, this study can be regarded as the first qualitative study which has attempted to shed light on learning of collocations from information processing perspective. The findings of this study have important implications for L2 specialists, instructional designers, teachers and learners.

\section{Literature Review}

\subsection{Field-dependent and field-independent characteristics}

The cognitive style of FD/FI was first proposed by Witkin (1962) and has enjoyed the most attention of all types of cognitive style by researchers and scholars. Indeed, it has been proved to have widespread implications for education, in general, and second/foreign language teaching and learning, in particular (Chappelle \& Heift, 2009; Dawson-Brew, 2010; Tinajero, Lemos, Araújo, Ferraces, \& Páramo, 2012; Witkin \& Goodenough, 1981, Yousefi, 2011). The FD/FI construct refers to individuals' contrasting tendencies towards codifying, assimilating and restructuring their surrounding environment (Witkin \& Goodenough, 1981). More particularly, the active analysis of information and breaking it into smaller parts, extracting the relevant details and identifying their patterns, and imposing a new structure based on their needs are what FI individuals typically tend to do when they approach a perceptual and problem-solving task. This is due to the fact that they put trust in internal cues, 
have greater restructuring aptitude and take an analytical approach to the received information (Carter, 1988; Chen \& Macredie, 2002; Hansen \& Stansfield, 1981; Stansfield \& Hansen, 1983). These particular characteristics enable them to spontaneously take multiple steps in information processing and therefore be actively involved in the process of learning.

In contrast, FD subjects, who are characterized by their especial sensitivity to external clues, tend to accept ideas or structures as they are presented (Jonassen \& Grabowski, 1993; Sözcü, İpek, \& Kinay, 2016; Tinajero \& Páramo, 1998). Indeed, they typically approach information holistically and therefore tend to focus their attention on the global picture rather than the details (Carter, 1988; Chen \& Macredie, 2002; Liu \& Reed, 1995). As a result, they generally fail in the tasks which require them to discern concepts and ideas embedded in a mass of information and concentrate on what is relevant or that which demands restructuring (Huang \& Chao, 2000; Tinajero et al., 2012).

Being aware of these characteristic differences can help educators understand students' learning behaviors and preferences: for example, as Witkin, Moore, Goodenough, and Cox (1977) point out, individualized learning is preferred by FI learners due to their tendencies towards intrinsic motivations, whereas a cooperative mode of learning sounds more enjoyable to FD learners due to their tendencies towards extrinsic motivations. Jones (1993) also contends that 'FDs are disadvantaged in unstructured situations, whereas FIs tend to provide their own structure more readily; FDs prefer directions and feedback, whereas FIs are less dependent on feedback; FDs rely more on others for information, whereas FIs are less influenced by peers' (p. 199).

In a word, FIs differ from FDs in the degree to which they are autonomous from their surrounding environment. The way that this degree of autonomy or dependency can affect different stages of information processing is of great importance in learning situations (Davis \& Cochran, 1989). This will be dealt with in more detail in the following section.

\subsection{Field-dependence/independence and information processing}

Cognitive psychologists developed information processing models and language learning specialists later employed them to study how learners attend to, encode, store and retrieve information. The origin of these models goes back to Atkinson and Shiffrin's (1968) stage theory model. This model, which is also known as three-stage information processing model, was modified by other researchers and is one of the currently most accepted models. According to this model, the three stages of information processing are attention, encoding/perception and memory (Davis \& Cochran, 1989). Messick (1970) was the first specialist who characterized FD and FI cognitive styles as two contrasting habits of information processing. This characterization has enjoyed widespread support and is regarded as one of the likeliest reasons for differences in learning (Tinajero et al., 2011; Yousefi, 2011).

Goodenough (1976) put forward a hypothesis that FDs and FIs differ significantly in attentional processes. According to his cue-salience hypothesis, the salient aspects or points of a stimulus can greatly dominate FDs' attention. Additionally, he contends that irrelevant cues in a more complex field can easily distract attention to the extent that they take no notice of many other features. However, he postulates that in the case of FIs, salient features are less dominating and irrelevant cues are less distracting. Goodenough's hypothesis has drawn support from various studies (e.g., Guisande, Páramo, Tinajero, \& Almeida, 2007; Rajagopalan, Modi, Kumar, Khushu, \& Mandal, 2015; Zhou, Zhou, Li, \& Zhang, 2015).

It is highly likely that these attentional differences lead into different working/short and long-term memory processes in terms of encoding and retrieving information (Davis \& Cochran, 1982, 1989). More particularly, Lang (1995) contends that those who have difficulty in selective attention are generally less capable of organizing and encoding information efficiently in their working memory. As a result, they retrieve the stored information from their long-term memory less effectively. This suggests that learners' attentional behavior is the predictor of their performance in the next stages of information processing. The storage and processing of 
information in the working memory is the second stage which is found to have a significant effect on learning outcomes (Alloway, Banner, \& Smith, 2010; Riding, Grimley, Dahraei, \& Banner, 2003). In this stage, the noticed information is stored temporarily and processed based on previous knowledge. The encoding of information into some meaningful constructs and their transfer to long-term memory, which occur in this stage, require a lot of thinking and cognitive processing. The working memory ability to do all these together varies considerably from person to person. It is therefore argued that variations in learning abilities are due to individual differences in working memory capacity. Learners with poor working memory skills fail in processing and storing the received information and are consequently at risk of learning difficulties (Alloway, Gathercole, Kirkwood, \& Elliott, 2009). This has been proved for different cognitive tasks including reading comprehension and vocabulary acquisition (Riding et al., 2003).

Some researchers such as Shan and Niannian (2006) and Spiro and Tirre (1980) conducted studies on FI and FD EFL learners and found FIs more successful in terms of storing information in their working memory due to their ability to reorganize the new information based on their prior knowledge. Likewise, Davis (1991) supports the point of view that FI learners attend to, analyze, encode and process information more efficiently than FDs. Wapner and Demick (2014) also contend that FD learners have great difficulty in isolating or attending to "relevant cues, particularly in the presence of distracting cues" and processing them in working memory (p. 166). In consequence, they "are less effective on a number of processes critical to learning" (ibid). These traits are especially amplified under high cognitive information load. This shows that FI learners have larger working memory capacity.

The last step in information processing is long-term memory. In this stage, "learners remember and apply information long after it has originally been learned" (Cao, 2006, p. 48). Researchers contend that long-term memory retrieval can be significantly influenced by the way information is encoded in working memory. They believe that to promote successful retrieval, this encoding must be meaningful and based on related previous knowledge (Driscoll, 2000; Gredler, 2001). This highlights the significant role of working memory capacity in interpreting and storing information in long-term memory. Accordingly, it can be hypothesized that if FD/FI cognitive style is related to attentional processes and working memory capacity, then FDs and FIs would also differ in long-term memory retrieval. Some studies examining this relationship have confirmed this hypothesis (Durso, Reardon, \& Jully, 1985; Pierce, 1983). Nevertheless, particularly in the area of language learning, few investigators have employed qualitative methods to confirm this hypothesis and provide a clear identification of learners' retrieval effort. This view that the depth of mental processing has a significant effect on the short-term and long-term memory retrieval is also reflected in Craik and Lockhart's (1972) 'Levels-of-Processing Effect Theory'. They believe that the deep levels of mental processing which involve pattern recognition lead to better retention. The relationship between these three general stages of the information processing model and cognitive characteristics of FD/FI individuals are shown in a figure by Daniel (1996, p. 35):

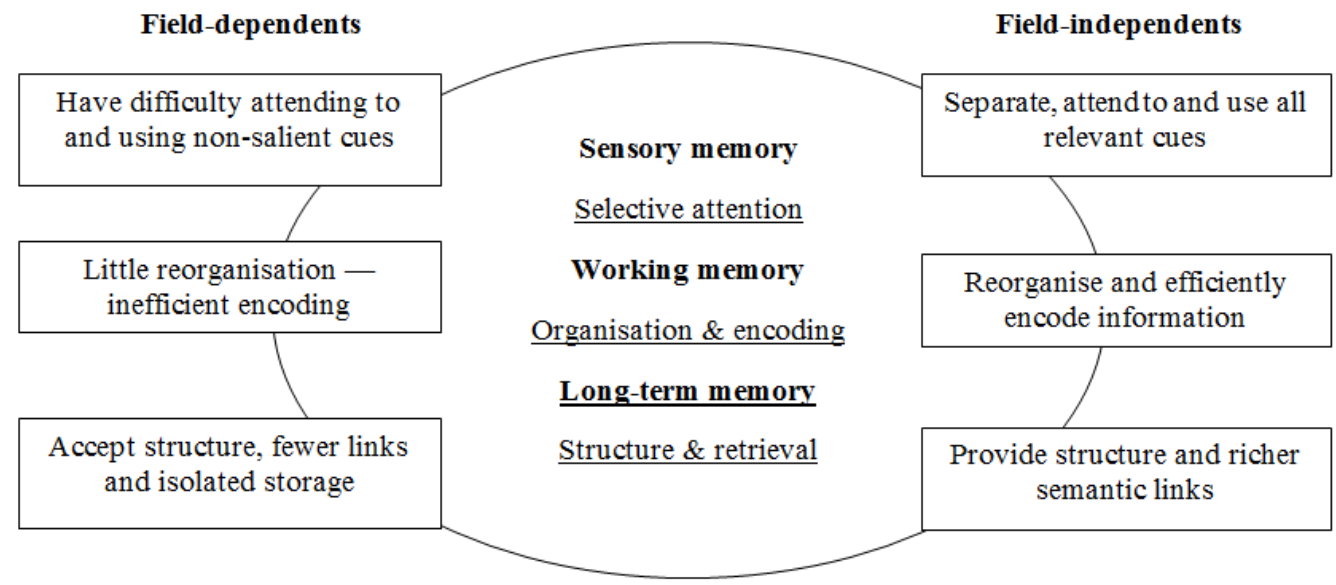

Figure 1. The relationship between cognitive processes and FD/FI cognitive style adapted from Daniels (1996) 
To sum up, review of the related literature reveals that FIs show different tendencies from FDs in attentional processes at the sensory-memory stage, encoding of information in the working memory, and retrieval processes of long-term memory (Davis \& Cochran, 1989; Mancy \& Reid, 2004; Tinajero \& Parama, 1998). Such distinction has important implications for L2 material and instructional designers.

\subsection{Field-dependence-independence and teaching methods}

Many researchers believe that students' individual learning styles can impact on the success or failure of an instructional program and aligning teaching methods with learners' cognitive styles, particularly FD/FI, can bring about optimum learning performance (Corno, 2008; Saracho, 2003; Tinajero et al., 2011). However, this view has had its opponents. Some researchers cast doubt on the claim that the FI/FD cognitive style dichotomy has widespread educational implications. They argue that there is little critical assessment of the original theory, so there is little empirical evidence proving it a robust construct. Dryer and Observe (1996), for instance, Griffiths and Sheen (1992) refer to FD/FI as a "theoretically flawed" concept and state that it "does not have and never has had any relevance for second language learning" (p. 133).

Despite Dryer and Observe's (1996) findings, most researchers contend that the differences in the characteristics of FD/FI learners suggest that they benefit from different types of instruction (Dabaghi \& Goharimehr, 2011; Muhammad, Daniel, \& Abdurauf, 2015; Sözcü et al., 2016; Wang, 2012). A study by Angeli (2013) on 119 sophomores, for example, indicated a significant relationship between the effectiveness of the employed instructional materials and the participants' FD/FI cognitive style. She concluded from her findings that instructional materials cannot "lead to effective instruction and successful intellectual performance for all learners" unless they are congruent with learners' FD/FI cognitive style (p. 228). Dabaghi and Goharimehr (2011) also studied the role of FD/FI cognitive style in learning some structural rules through two grammar teaching methods. They reported that the FD participants did better with the integrative method, whereas the FIs learned better through the discrete-point method. By the same token, findings of Abraham's (1983) study indicated that the FD students benefited from the inductive method of teaching grammar; the FIs, the deductive approach.

FD/FI cognitive style advocates, however, have not conducted enough empirical research to clearly show the distinction between FDs and FIs in the specific processes involved in learning through different instructional designs, particularly in the area of language learning and teaching. Indeed, most of the conducted studies have provided a very global picture of FD/FI dichotomy since they have not employed information processing paradigms as well as appropriate qualitative methods to throw light on FD and FI learners' mental processes. This is while performance differences between FDs and FIs are believed to be best explained by means of information processing constructs (Davis \& Cochran, 1989). Hence, there is a need for more rigorous research in this area. For this reason, the present research used the information processing model to study FDs and FIs' learning processes. To provide a clear and accurate identification of the processes involved, three qualitative methods were employed.

In light of the aforementioned characteristics of FD learners, FDs seem to benefit from teaching methods which provide them with the highest degree of support and guidance. Indeed, they need an external instructional support which helps them to identify the learning goals and to maintain their direction towards achieving them. They also need to be taught how to organize and store information in their working memory in order not to have difficulty in the retrieval stage. FDs benefit greatly if they are given an external structure for their learning (Tinajero et al., 2011). Furthermore, some scholars suggest that since FDs are amore extrinsically motivated, providing feedback and incentives can affect their learning performance positively. It has been argued that the superiority of FIs over FDs in formal classroom settings can be decreased or even eliminated by the means of using feedback and rewards as external reinforcements (Adegoke, 2011; Hashemian \& Farhang-Ju, 2018)

Conversely, FI learners, who are more independent and 'intrinsically motivated with self-directed goals' (Cassidy, 2004, p. 425), seem to be able to structure their own learning and develop their own strategies with 
Field-dependent/independent cognitive style preferences of EFL learners in an implicit learning task

minimum need for teacher direction. Therefore, they can perform well in lesson designs which require more autonomy on the part of the learners (Jonassen \& Grabowski, 1993; Tinajero et al., 2011). In addition, the review of the available research reveals that ambiguity tolerance, great guessing ability and good analytical skills are highly correlated with FI learners (Akbari, Jafar, \& Asadi, 2006; Hanson \& Standfield, 1981).

These characteristics can explain why findings of language testing researchers, such as Chapelle and Roberts (1986) and Bachman (1990), showed a positive relationship between FI and cloze test. FIs are more successful than FDs in tasks where learners are supposed to attend to details, analyze the input, impose their own structure and categorize the information in their working memory autonomously. Hence, it can be assumed that in comparison to FD learners, FIs can benefit more from teaching methods such as input flood treatment where the goal is to extract and learn target features embedded in the input without direct instruction. In the case of input-flood treatment, no rigorous studies have been found examining this assumption empirically. Furthermore, as mentioned before, thus far studies in the area of FD/FI cognitive style have been mainly focused on grammar, vocabulary acquisition and the four skills of speaking, reading, listening and writing, but no research has examined the role of learners' cognitive style in collocation acquisition. Hence, the present study aimed to address these gaps in the literature. The current research is indeed an initial attempt to shed light on information processing components of learning collocations through input-flood technique with regard to learners' FD/FI cognitive style.

\subsection{Research question}

The present research aimed to explore possible differences between FD and FI learners in learning collocations through input-flood treatment from information processing perspective. More precisely, it was attempted to find out if their particular characteristics and abilities impact upon different stages of information processing and consequently the learning outcome. With regard to the above considerations, the following question was raised and pursued to be answered in this study:

$>\quad$ Do FD and FI learners differ in the way they process information in the task of learning collocations through input-flood treatment?

\section{Method}

\subsection{Research design}

In this study, a qualitative approach design was employed to cast light onto the processes involved in the way the FD and FI learners approached the task of learning the target collocations embedded in the flooded texts. To achieve this aim, three qualitative methods, namely a retrospective-reflective task as a form of think-aloud method, tests of intake and semi-structured interviews were used. As suggested by Rankin (1988), each participant was treated as a small case study whose mental experiences were thoroughly examined.

\subsection{Participants}

The accessible population of the study consisted of Iranian freshmen majoring in different branches of engineering at Petroleum University of Technology. Since it was not practical to appoint the same lecturer for all the students, only 50 students out of 112 could be assigned to the classes which would be taught by the same lecturer. Therefore, 50 students were left for the study. Assigning the same instructor for all the participants of the study was indeed one of the variables that if it had not been controlled, it could have acted like an extraneous variable and might have affected the results of the study.

To select the eligible participants out of these 50 students, they, who had already been classified as intermediate language learners by the placement test of the university, were given, first, a TOEFL test in order to 
re-examine their English proficiency and ascertain that they are truly at the intermediate level. Then, in order to determine the homogeneity of the learners in terms of their knowledge of collocation and also their familiarity with the concept of collocation, the learners took a test of collocation and answered the questions of a background questionnaire regarding their past vocabulary learning experience. Finally, the same students were asked to take a psychological test called the Group Embedded Figures Test (GEFT). Based on their GEFT scores, the students were classified into FD, FI, and a third group of field-neutral (FN) which was not of great concern in this study.

The learners whose knowledge of collocation was not on a par with the majority of the leaners (i.e. too high or too low) and those who fell in the category of field-neutral were excluded $(n=16)$. Thus, 34 students (16 FI and 18 FD learners) were selected to serve as the participants of this research. All the participants were asked to do the retrospective-reflective task as well as the tests of intake. Then, both FD and FI learners were interviewed on a voluntary basis. The researcher reached the data saturation point with eight learners (four FD and four FI learners). Their demographic information is described in Table 1. In the present research in which the student participants were needed to be interviewed twice, their willing voluntary participation was of great help.

\section{Table 1}

Demographic Information of the Student Participants

\begin{tabular}{clcccc}
\hline No & \multicolumn{1}{c}{ Name } & Gender & Age & Years studying English & Cognitive style \\
\hline 1 & Ali & M & 19 & 4 & FI \\
2 & samaneh & F & 18 & 4.5 & FI \\
3 & Donya & F & 18 & 3.5 & FI \\
4 & Armin & M & 22 & 5 & FI \\
5 & Mehdi & M & 19 & 4 & FD \\
6 & Mehran & M & 20 & 4.5 & FD \\
7 & Mahmoud & M & 19 & 5 & FD \\
8 & Negar & F & 19 & 4 & FD \\
\hline
\end{tabular}

\subsection{Instruments}

The first instrument used in the present study was a TOEFL test adopted from Barron (2004). The participants had already been classified as intermediate learners by the placement test of the university. However, this test was administered to determine their level of proficiency again and also ensure the homogeneity of the participants in terms of their English general knowledge prior to the experiment. The reliability of the test was calculated as .90 .

As mentioned before, to determine the cognitive style of the participants in terms of their FD/FI tendencies, the Group Embedded Figures Test (GEFT) was employed in this study. This test was developed by Witkin et al. (1971) and its reliability was reported to be .82. Following Nilforooshan and Afghari (2007), the split half method was implemented to calculate the reliability of the test which was found to be .80 in the current research. In this paper-and-pencil test, the subjects were required to recognize some simple forms which were hidden in complex geometric figures. Each of the simple forms that could be identified correctly received one point. Hence, the scores ranged between 0 and 18. In the present study, the criterion suggested by Scardamalia (1977) was used for determining the FD/FI cognitive styles of the subjects. According to this criterion, the subjects who scored more than $1 / 4 \mathrm{SD}$ above the mean for the sample population were classified as FI and those who scored less than $1 / 4 \mathrm{SD}$ below the mean were considered FD.

In addition to the above tests, a questionnaire consisting of some open-ended questions was administered to obtain background information on the participants' past vocabulary learning experience. This questionnaire was employed prior to the experiment to ensure that only those who had not been made aware of the concept of collocation and had not experienced learning linguistic forms through input-enhancement techniques before this study would participate in the current research. The questionnaire was piloted with a similar group of students. 
The respondents were asked to not only answer the questions but also inform the researcher of any ambiguity hindering their comprehension. Since none of the respondents made such comments, it was concluded that the language of the questionnaire was clear and understandable enough. The responses also indicated that the questions could elicit the required information.

Furthermore, three collocation tests, which were designed by the researcher, were administered as the pre, immediate and delayed post-test to learn about the FD and FI participant's knowledge of collocation before the treatment as well as their short-term and long-term memory retrieval after the treatment. Each of these tests was composed of two parts which measured the learners' both receptive and productive knowledge of the target collocations through gap-filling and multiple-choice items. In order to eliminate the effect of the practice factor, the contexts of the test items were completely different in these three tests.

To ensure the reliability and validity of these researcher-made collocation tests, the steps suggested by Ary, Jacobs, Sorensen, and Razavieh (2010) were followed. Most of the test items were designed by the researcher and even those few adopted from Koya (2003) and Shokouhi and Mirsalari (2010) were modified. To design the multiple-choice questions, the test items were, first, given to a large group of Iranian EFL learners at intermediate level in various language centers in the format of gap-filling test. The learners' answers to these test items were carefully examined. The researcher made a list of incorrect answers from these test items. Then she chose the most common ones as the distractors of the multiple-choice items. It is important to note that the researcher used BBI Dictionary of English Word Combinations (Benson et al., 1997), Longman Dictionary of Contemporary English, Oxford Collocations Dictionary as well as three online corpora (i.e. British National Corpus, Corpus of Contemporary American English (COCA) and VLC Web Concordancer) to ensure the accuracy or inaccuracy of the collocations produced by the learners in the gap-filling test items.

Then the tests were given to two native speakers of English to check the questions in terms of the accuracy and appropriateness of the contexts as well as the alternatives in the multiple-choice test. They were also asked to write as many correct answers as possible for the gap-filling questions. The purpose was to gather all the possible correct collocaional fields of the target items for the future reference in the actual study. Both native speakers suggested some modifications. After making the required modifications, the tests were piloted and the reliability of each was assessed using the Cronbach's alpha. The results indicated an acceptable degree of reliability for the pre-, immediate and delayed post-test. The $\mathrm{R}$ values were $0.79,0.81$ and 0.78 respectively.

Moreover, some reading texts were used as the treatment materials. These texts had instances of the target collocations artificially increased up to 8 times since according to Durrant and Schmitt (2010), collocations need to be seen around at least 8 times in order to be learned. Another instrument employed in this study is the test of intake in which all the learners were required to tick those word items they had seen in the texts that they had just read. Learners' degree of the accuracy of the episodic memory discrimination for the target forms can show how superficially or deeply those forms were processed (Pulido, 2004). This test consisted of the three target collocations from the text, three word items from the text which were relevant to the theme as well as six word items which were relevant to the theme, but not mentioned in the text. The decision regarding selecting the word items other than the target collocations were made after consulting the panel of experts. This test was piloted and no specific problems were found. This could be due to the fact that it was simple to be completed. Additionally, the learners were asked to perform the retrospective-reflective task as a form of think-aloud method, not immediately recorded. They were asked to write everything that they noticed, felt, saw, asked, did and understood during reading the texts. This task was also piloted to see if it could successfully elicit the required information from the learners. The results of the pilot accentuated the need for more complete explanation about how to perform the task in order to minimize the possibility of confusion in the actual study. Furthermore, the pilot findings indicated that there were some ambiguities in the retrospective-reflective reports which needed to be clarified by the participants. In addition, it was found that the reports could not provide the required detailed information regarding how the learners attended to the noticed collocations in terms of storing and retrieving them. These findings necessitated interviewing the participants. 
Finally, two interview protocols were used to ask the participants some specific questions regarding the missing/ambiguous parts of their retrospective-reflective reports as well as the processes involved in the storage and retrieval of the target collocations. The interview protocols were piloted to ensure the clarity of the questions and to see if these questions could serve their purposes. A useful time limit was determined per interview session. The interview protocols were piloted using three FD and three FI learners who were very similar to the target participants. The pilot interviews indicated that the respondents misunderstood some questions or needed clarification. Hence, the researcher modified the questions in order to minimize the possibility of such problems in the interview sessions of the main study.

In the current study, the validity of the employed instruments, which, according to Hatch and Farhady (1982), is a relative issue, was determined by a panel of experts. As stated by Creswell (2008), "researchers evaluate content validity by examining the plan and the procedures used in constructing the instrument. Typically researchers go to a panel of judges or experts and have them identify whether the questions are valid" (p. 172). Thus, a panel of experts was asked to ascertain the content and face validity of the background questionnaire, interview questions, collocation tests, the retrospective-reflective task, the test of GEFT, the test of intake and the reading texts. In addition, they were consulted about the selected target collocations. These experts were L2 specialists holding a $\mathrm{PhD}$. They were given all the necessary details regarding how to validate the instruments in terms of face and content in form of a letter. Any modifications to the instruments were made after consultation with these experts.

\subsection{Procedure}

This study was carried out in one of the undergraduate English Language courses offered in the second semester at Petroleum University of Technology within four months and a half (February-June 2017). Excluding the test sessions, the treatment period was composed of twenty six sessions held twice a week. Both FD and FI students were taught collocations implicitly through the input-flood technique by the same instructor within the same time span. The flooded reading texts were used as the treatment materials every other session. Indeed, there was no explicit mention of the target collocations and the students were asked to read the texts only for comprehension purposes. The texts were followed by different kinds of exercises including comprehension questions, true/false sentences, giving summary, matching information and unscrambling sentences in the same and following sessions.

To ascertain whether the input flood technique served its purpose and successfully attracted the learners' attention to the target collocations, a test of intake was, first, administered immediately after reading the texts in the first and last treatment session. It took approximately 2 minutes for all the participants to complete it. Following that in both first and last treatment sessions, the subjects were asked to write their retrospective-reflective reports. It is important to note that the participants had been taught how to report and verbalize their mental processes prior to reading the texts. The purpose of administrating the retrospective-reflective task and test of intake in both first and last treatment sessions was to see if the learners' experience of reading different texts flooded with collocations during the treatment could bring about any significant changes in their attentional processes. They were asked to use the language which they were most comfortable using since the researcher did not want to let language be a barrier to expressing their thoughts and ideas. As expected, all of them preferred Persian (their L1).

Like the pilot study, the participants' reports in the actual study mainly shed light on the learners' attentional processes (i.e. the first stage of information processing). They did not provide the required detailed information about how the noticed collocations were stored and retrieved. This highlighted the need for interviewing the students in this regard. As the recall and retrieval of the target collocations were attributed to the learners' performance in the immediate and delayed post-tests, the interviews were conducted after these two post-tests. The immediate post-test was administered after the last treatment session. Two weeks after that, the delayed post-test was administered. 
Field-dependent/independent cognitive style preferences of EFL learners in an implicit learning task

Some retrospective interview questions were added to the protocol after collecting, reading and coding the participants' retrospective-reflective reports in order to elicit more information or clarification on their thought/attentional processes. The one-to-one semi structured in-depth interviews with the FD and FI learner interviewees were conducted in two sessions. The first interview was conducted after the immediate post-tests and lasted for 35 to 45 minutes. The second interview, of 15 to 25 minutes, was carried out after the delayed post-test. In the first interview session, the interviewer did not mention anything about the concept of collocation and the main purpose of the employed treatment. The interviewees were asked indirect and more general questions about the treatment period and the reading texts. Then, they were asked some indirect but detailed questions regarding their performance in the immediate post-test of collocation as well as their retrospective-reflective reports. However, in the second interview session conducted after the delayed post-tests, the interviewer explained the real purpose of the texts during the treatment period and asked the interviewees some direct questions about the impact of the employed teaching method on their knowledge of collocation and their performance in the delayed post-test. Moreover, the learner interviewees were asked some direct and detailed questions about their thought processes while reading the texts. These questions intended to support the findings from the retrospective-reflective reports and thus gain a deeper and clearer insight into the way the FDs and FIs processed the target collocations.

Similar to the retrospective-reflective task, the interviewees were allowed to converse in Persian (their L1) due to their preference. In order to facilitate recall, the learners' pre- and post-treatment tests, the reading texts and their written verbalized thoughts were given to the interviewees whenever they were needed. They were also asked to bring their notes about these texts, if any, on the interview days. It is worth noting that the respondents' permission for recording the interviews was sought. For the purpose of confidentiality, the researcher asked the participants to choose pseudonyms.

\subsection{Data analysis}

In the case of the data obtained from the retrospective-reflective task and the interviews, the typical procedures of qualitative data analysis were employed (Ary et al., 2010). More precisely, the five steps, viz. familiarization, a thematic framework identification, indexing, charting, mapping and interpretation, suggested by Krueger (1994) in his 'framework analysis' were followed. First, the researcher read the participants' verbal reports several times in order to familiarize herself with the collected data. Then, she attempted to come up with a framework for analysis. As suggested by Ary et al. (2010), a researcher can, first, approach the qualitative data with a set of prior themes derived from the related literature and then add the new themes, if any, emerged from the data.

To achieve the aim of the study, the researcher began with the concepts that exist in the three-stage model of information processing. As mentioned before, according to this model, the three stages of information processing are attentional processes in the sensory-memory stage, storage of information in working memory, and recall and retrieval processes of short- and long-term memory (Davis \& Cochran, 1989; Tinajero \& Parama, 1997). Hence, these three stages formed the initial framework for analyzing the data. The retrospective-reflective reports were scrutinized in detail and the sections related to each particular theme (i.e. stage) were identified/coded and indexed. More precisely, the data provided by the retrospective reflective reports were related to the first two stages of information processing. The analysis of these data, however, revealed that the reports provided more information about the first stage and the data related to the second stage required more clarification and details. Thus, much of these data fell into the category of attentional processes, and the rest fitted into the category of storage of information in the working memory. The ambiguous or missing parts were also indexed in order to be added to the questions of the follow-up interview protocols.

The same coding procedures were followed in the case of the data obtained from the interviews. The interview transcripts provided detailed data for all the stages of information processing, so they fitted into the categories of attentional processes, storage of information in working memory and recall and retrieval processes 
of short- and long-term memory. In addition, the researcher looked for the concepts which could be drawn from both sources of data (i.e. the retrospective-reflective reports and the interviews). The analysis of the data revealed that in the first stage of processing the information, the participants attended to the target collocations in three ways. These attentional manners were labeled 'attention', 'ignoring' and 'no notice' approaches as the subheadings under the category of attentional processes. Furthermore, careful scrutiny of the data indicated that the perception/ encoding of the target features occurred at two different levels/depths. Level 1 was mere attention to the semantics of the target collocations and level 2 consisted of L1-L2 contrastive analysis as well as activating L2 prior knowledge. These two levels belonged in the category of storage of information in working memory. Review of the related literature also revealed different levels or depths for processing information in working memory (Craik \& Lockhart, 1972; Mahdavian \& Kormi-Nouri, 2008).

Following the coding procedure, the indexed/coded data were arranged according to the charts of the themes. These charts, as suggested by Krueger (1994), were comprised of headings and sub-headings. Finally, the key ideas which were arranged in the charts were analyzed. In the case of the test of intake, the purpose was only to find out whether the participants had noticed the target collocations while reading the texts in order to gain more insight into their attentional processes. Hence, their correct ticks in the case of the target collocations were simply counted. The results of this test were only used as supplements to the retrospective-reflective task results.

To ensure the validity of the qualitative data obtained from the interviews and reflective tasks, peer debriefing technique was employed (Ary et al., 2010). The raw qualitative data of the interviews and reflective task as well as the researchers' own explanations and interpretations were given to a peer who was asked to review them and provide the researcher with comments. The peer had a PhD in Teaching English as a Foreign Language and was interested in the same research area.

For the purpose of ensuring the reliability issue in the present research, the inter-rater method was employed (Creswell, 2007). The researcher's coding of the data was compared with that of the peer who had been asked to code the data. The peer had been, first, familiarized with the coding system, and, then, started coding the data. Any disagreement between the researcher and the peer in terms of coding the data was discussed afterwards. Following McMillan and Schumacher (2010), to ensure the inter-rater agreement for the coding work, the total number of agreements was divided by the total number of agreements plus disagreements and then multiplied by 100. In the current study, the inter-rater reliability for coding of the data obtained from the reflective reports and interviews were found to be 90 and .91 respectively.

\section{Results and discussion}

The analysis of the data obtained from the employed qualitative methods revealed that the FDs and FIs differed in the way they process the information in the flooded texts. More precisely, the results empirically supported previous researchers' (e.g. Davis \& Cochran, 1989; Tinajero \& Parama, 1997) assertions regarding the marked differences between FD and FI learners in the three stages of information processing, viz attentional processes in the sensory-memory stage, the storage of information in working memory, and recall and retrieval processes of short- and long-term memory. Each of these stages will be dealt with in the subsequent sections.

\subsection{Attentional processes}

Prior to reporting the qualitative results, it is important to note that comparing both FD and FI participants' first reports and intake test results with their second ones performed in the last treatment session indicated that the learners' experience of reading different texts during the treatment period could not bring about any significant changes in their attentional processes in terms of the target collocations.

The FI participants could recognize the target collocations in the tests of intake. This showed that they noticed all the target collocations. However, the analysis of the data obtained from the retrospective-reflective reports and the follow-up interviews indicated that they attended to these target collocations in two different 
Field-dependent/independent cognitive style preferences of EFL learners in an implicit learning task

ways. These two attentional manners were labeled 'attention' and 'ignoring' approaches emerging from the qualitative data (see Table 2).

\section{Table 2}

\section{FI Learners' Attentional Manners}

\begin{tabular}{ll}
\hline \multicolumn{1}{c}{ Manner } & \multicolumn{1}{c}{ Example } \\
\hline $\begin{array}{l}\text { Attention approach: } \\
\text { the learners paid attention to the linguistic or }\end{array}$ & $\begin{array}{l}\text { e.g / ....the blame lies with the parents.../ I knew the } \\
\text { meaning of lies but I couldn't understand its meaning } \\
\text { semantic features of the noticed collocations }\end{array}$ \\
$\begin{array}{l}\text { here... the combination of blame and lies sounded new } \\
\text { to me... /(Donya, one of the FI participants) }\end{array}$ \\
$\begin{array}{l}\text { Ignoring approach: } \\
\text { e.g. ... start a family... /Well, I saw these two words } \\
\text { collocations }\end{array}$ \\
$\begin{array}{l}\text { many times in the text but there was no need to focus on } \\
\text { them ... I knew their meanings/(Ali, one of the FI } \\
\text { participants) }\end{array}$ \\
\hline
\end{tabular}

However, in the case of the FD participants, the results revealed that they did not take notice of all the target collocations. Thus, in those cases, their attentional manner was labeled as 'no notice' approach (see Table 3).

Table 3

FD Learners' Attentional Manners

\begin{tabular}{ll}
\hline \multicolumn{1}{c}{ Manner } & \multicolumn{1}{c}{ Example } \\
\hline $\begin{array}{l}\text { Attention approach: } \\
\text { the learners paid attention to the linguistic or } \\
\text { semantic features of the noticed collocations }\end{array}$ & $\begin{array}{l}\text { e.g. / ... juvenile delinquency .../I didn't know these two } \\
\text { words ...They were important for understanding the text } \\
\text { so I looked them up in my mobile dictionary/ } \\
\text { (Mahmoud, one of the FD participants) }\end{array}$ \\
$\begin{array}{l}\text { Ignoring approach: } \\
\text { the learners did not pay attention to the noticed } \\
\text { collocations }\end{array}$ & $\begin{array}{l}\text { e.g. . petty crime...... /I didn't know the meaning of } \\
\text { understand the passage without knowing its meaning/ } \\
\text { (Negar, one of the FD participants) }\end{array}$ \\
$\begin{array}{l}\text { No notice approach: } \\
\text { the learner did not notice the target collocations }\end{array}$ & $\begin{array}{l}\text { e.g./..explain to.../While doing the intake test, I } \\
\text { couldn't remember whether I saw this verb or not... may } \\
\text { be because there were many verbs in the text/(Mehdi, } \\
\text { one of the FD participants) }\end{array}$ \\
\end{tabular}

The analysis of the data revealed that the FDs took 'no notice' and 'ignoring' approaches when they encountered most of the target collocations. They did not mention anything about most of the target collocations in their retrospective-reflective reports or even in answer to the immediate follow-up interview questions concerning what attracted their attention in the texts or what they learned from the texts, in general, and the words they encountered, in particular. When they were directly asked about the target collocations after the delayed post-tests, they stated that the increase in the amount of exposure to these chunks in the texts did not draw their attention to most of them since, firstly, they posed no serious difficulties for their general comprehension of the text and, secondly, they were not asked to do so. More particularly, since they were only asked to read the texts for meaning, they approached the texts holistically and only attempted to get the gist of the texts and find the key ideas in order to do the required exercises (e.g. giving summary and answering true/false sentences). The results of their tests of intake also indicated that they did not pay that much attention to the target collocations.

Such findings lend empirical support to the assertion of some researchers, such as Jonassen and Grabowski (1993), Tinajero and Páramo (1998), Chen and Macredie (2002) and Liu and Reed (1995), that FD people tend to take a holistic approach to processing the input they are exposed to. Since they are more influenced by the external standards and reinforcement, they tend to accept the structure of information as it is presented or do exactly what they are asked by authority figures. For example, Mehran, one of the FD participants, stated that:

We were asked to prepare a summary... so I underlined the important sentences while reading.... 
Hamed Mahvelati, E.

after that I was looking for the answers to the truelfalse questions.... I skipped the unknown

words as I was going through the text unless they affected my comprehension.

In accordance with the previous research (e.g. Huang \& Chao, 2000; Tinajero et al., 2012), these findings suggest that FDs cannot perform well in a learning task which demands focus on the details of the input or restructuring of the received information in the absence of external support.

On the contrary, the FIs were found to be more independent and active in perceiving and processing the received information. They adopted 'attention' approach more than 'ignoring' approach. Although they were only asked to read the texts for meaning, they took an analytical approach and actively analyzed the texts, broke them into smaller parts and extracted the linguistic features, particularly the target collocations as a result of the artificial increase in their incidences in the texts, as well as the key ideas autonomously. This means that they were less dominated by the externally defined goals and their behavior towards the learning tasks was more affected by their own needs and values. This concurs with the findings of other researchers in the related literature: for example, Carter (1988), Cassidy (2004), Chen and Macredie (2002), Guisande et al. (2007), Hansen and Stansfield, 1981; Rajagopalan et al. (2015), Stansfield and Hansen (1983), Witkin and Goodenough (1981) as well as Zhou et al. (2015). For instance, Samaneh, one of the FI participants, stated that:

As I was reading the text to see what it was about, I came across the phrase 'the blame lies with' repeatedly... I didn't try to find its meaning when I saw it for first time in the text but because it was repeated in many sentences I looked it up in my mobile dictionary ... I didn't know that the meaning of lies changed when it was used with 'blame'...

\subsection{The storage of information in the working memory}

As reported in the previous section, the participants used the attention strategy for some of the target collocations. The next step was to find out how they interacted with these target features in terms of organizing, encoding and storing in their working memory. This was labeled the storage of information in the working memory as a category emerging from the data and also the related literature. The retrospective-reflective reports did not provide the researcher with enough information regarding this issue. Thus, the follow-up interviews were conducted in order to figure out the depth of the participants' processes. The data revealed the two following levels of the participants' processes (see Table 4):

\section{Table 4}

Levels of the Participants' Processes

\begin{tabular}{llll}
\hline & \multicolumn{1}{c}{ Level 1 } & Level 2 \\
\hline Participants & $\begin{array}{l}\text { mere attention to the semantics of the } \\
\text { target collocations in order to } \\
\text { understand the idea of the content }\end{array}$ & $\begin{array}{l}\text { L1-L2 contrastive } \\
\text { analysis }\end{array}$ & activating L2 prior knowledge \\
\hline FDs & $\begin{array}{l}\text { I looked them up in my mobile } \\
\text { dictionary... or asked the } \\
\text { teacher....then translated the whole } \\
\text { sentence. (Negar, one of the FD } \\
\text { participants) }\end{array}$ & I used my mobile dictionary to figure \\
out their meanings in the sentences & $\begin{array}{l}\text { The Persian equivalents } \\
\text { of some of them had } \\
\text { completely different } \\
\text { structures... }\end{array}$ & $\begin{array}{l}\text { I didn't know that some words } \\
\text { could be used together.... for } \\
\text { instance, I knew the phrase go mad } \\
\text { but I didn't know that go could be } \\
\text { also used with bald... So I wrote it } \\
\text { down in my vocabulary notebook } \\
\text { (Ali, one of the FI participants) }\end{array}$ \\
\hline
\end{tabular}

As the above table shows, Level 2 refers to a deeper processing of the target features. Not surprisingly, the FIs showed the signs of both levels, but the FDs showed only the signs of Level 1 processing. More precisely, the FI participants reorganized the new information and forged links with their prior related information in both 
Field-dependent/independent cognitive style preferences of EFL learners in an implicit learning task

L1 and L2. They tried to find the L1 equivalents for these combinations, made a quick L1-L2 contrastive analysis in their minds and also activated their L2 prior knowledge (Level 2). Finally, they updated their prior knowledge based on the new information.

However, the FDs were found not to be as organized as the FIs in storing the new information in their working memory. Unlike the FIs, they did not restructure or reorganize the new information to link it with the existing knowledge in their working memories. They merely paid attention to the semantics of these target collocations in order to get the idea of the content (Level 1).

In line with these findings is Shan and Niannian's (2006) study which showed that FI learners stored information in their memory more efficiently because of their ability to reorganize the new information to provide a context for prior knowledge' (p. 60). According to the existing literature in the area of semantic network models, this link facilitates meaningful learning. Spiro and Tirre (1980) also consider FIs' use of previous information as a means of recall enhancement to be one of the main reasons for their superior long-term memory retrieval.

\subsection{The recall and retrieval processes of short- and long-term memory}

To probe more deeply into the issue of the learners' short-term memory recall and long-term memory retrieval of the target collocations, both FD and FI participants were interviewed after the immediate and delayed post-tests. In both interview sessions, the respondents were asked to explain about the level of the difficulty of the post-tests as well as their performance in comparison to the pre-test.

The results showed that the FIs recalled and retrieved the target collocations, especially the ones they had processed more deeply while reading the texts, more efficiently and more confidently. In the post-tests, they remembered that they had seen many of the test items earlier in the texts. Although they could not remember the collocational fields of all of the noticed collocations correctly, they could recall and retrieve a greater number than the FDs. Armin was one of the FI learners whose response is as follows:

I saw many of them ........ in the texts ..... but I could remember only some of them vividly....because I had written them in my book and had revised them for the final exam...

The FD interviewees, on the other hand, merely remembered that they had seen some of the target collocations earlier in the texts, but since they had found them too simple in terms of semantics, they skipped most of them (i.e. ignoring strategy). Hence, they vaguely remembered their collocational fields even in the test taken immediately after the treatment finished. They answered most of the items based on the meanings of the words or their levels of familiarity and were not very confident about many of their responses. The comparison of the FI and FD participants' collocation post-test scores with their pre-test scores corroborated the FIs' superiority over the FDs in terms of developing their knowledge of collocation through input-flood treatment. More particularly, the FD participants' scores did not show any significant improvement in their knowledge of collocation.

These findings are in line with the previous research in the related literature reporting that FIs are associated with more efficient memory retrieval due to the organization and structuring processes they employ to store and retrieve information (Davis \& Cochran, 1982; Witkin \& Goodenough, 1981). Consistent with these findings is Mancy and Reid (2004) who contend that contrary to FDs, FIs do not clutter their working memory with irrelevant features. They process and store information in a more organized way; as a result, they have more efficient access to the stored information. These findings also corroborate Lang's (1995) assertion that working memory processes of those who have less difficulty with selective attention are generally more efficient and their long-term memory retrieval is, consequently, more effective. Additionally, these findings empirically support Craik and Lockhart's (1972) 'Levels-of-Processing Effect Theory' which suggests that deeper levels of mental processing lead to longer-lasting and stronger memory retrieval than shallow levels of processing. 
All things considered, it can be concluded that the degree to which the input-flood technique could facilitate collocation knowledge development depended upon the learners' FD/FI cognitive tendencies. These findings, therefore, offer empirical evidence to the theories of FD/FI cognitive style which argue that FIs outperform FDs in the learning tasks that require learners to autonomously discern and learn the target items embedded in the received input in the absence of explicit instruction or feedback (Jonassen \& Grabowski, 1993; Tinajero et al., 2011; Tinajero et al., 2012). This is also in line with Tinajero et al.'s (2011) assertion that FDs need an external instructional support which helps them to identify the learning goals and to maintain their direction towards achieving them. They also need to be taught how to organize and store the information in their working memory in order not to have difficulty in the retrieval stage. In other words, FDs benefit greatly if they are given an external structure for their learning. This is in direct contrast to the theoretical claim of Griffith and Sheen (1992) who denied the significant role of the learners' cognitive style of FD/FI in L2 learning. Moreover, the results of this research do not support the findings of Dryer and Observe (1996) that the students' FD/FI cognitive style cannot affect the effectiveness of a teaching method in a learning setting.

\section{Conclusion and implications}

The findings revealed that flooding the texts increased the chance of noticing the target collocations for the FI learners due to their analytical orientation towards information processing and their reliance on self-defined goals. These characteristics helped them perceive and process the texts independently and actively. Nevertheless, such exposure alone was not sufficient for the FDs to notice or pay sufficient attention to the collocations. This was due to their holistic approach to perceiving and processing the texts as well as lack of externally defined goals and reinforcements. Moreover, the FIs were found to be more organized in storing the information than their FD counterparts. They analyzed and restructured the new information to fit well into the prior related knowledge in their working memory. As a result, they showed a deeper level of recall and retention of the target collocations.

The superiority of the FIs over the FDs in all the above mentioned stages of information processing was found to be the main reason for their better performance in the implicit lesson design of input flood in which the learners were supposed to extract and learn the target linguistic features within the texts without the teacher's direct interference. The findings regarding the FDs, however, showed that they were in need of external instructional support. This suggests that input-flood treatment cannot be rejected or accepted as an inefficient/efficient teaching method without considering the role of learners' individual FD/FI cognitive style. This means that the effectiveness of an instructional method can be significantly affected by learners' individual cognitive style differences. Thus, this can be concluded that learners' individual differences in their preferred ways of approaching information have significant effects on the process of teaching and learning. However, in order to shed more light on this issue, clearly, more research is needed to be conducted in this area.

The findings of this study can have important implications for the instructional designers and curriculum developers in the field of second/foreign language education, in general, and collocation acquisition, in particular, to devise effective teaching methods which meet the special learning needs of FDs and also develop the abilities of FI learners. More precisely, the findings of the present study suggest that FD tendencies hinder collocation learning through methods which require learners to be self-directed and independent. Indeed, they only benefit from learning activities and exercises in which learners' attention is directly drawn to collocations in a highly structured setting. Thus, the input-flood method cannot bring about the desired learning outcomes in relation to collocations in typical L2 classrooms in which there are learners with different FD/FI tendencies. It is therefore recommended that even if such implicit methods are employed, they should be combined with explicit attention drawing techniques or intervention.

These findings also provide language teachers with useful information about the characteristics of FD and FI learners and suggest that teachers should learn about their students' individual differences, in general, and FD/FI cognitive style, in particular, in order to find out each learner's specific area of difficulty and help him/her 
Field-dependent/independent cognitive style preferences of EFL learners in an implicit learning task

accordingly. This helps teachers to select appropriate collocation teaching methodologies and strategies to meet the needs of each type, particularly FD learners who was found to be inferior to FI learners in terms of autonomous processing of the received input. Such awareness can also develop good teacher-student rapport. The findings of the current research revealed that the FDs' learning goals in the reading tasks were highly influenced by the teacher's standards and reinforcements. Thus, unlike the FIs, the FD learners did not pay attention to the target collocations despite the artificial increase in their frequency in the texts. This highlights the important role of teachers in FDs' learning outcomes.

It was also found that the co-occurrence of words in collocations was not salient enough to attract the attention of the FD learners. This suggests that FD language learners cannot acquire collocations implicitly through the input-flood technique without any explicit forms of instruction. These findings therefore suggest that L2 teachers should employ more supportive and directive teaching methods to help FD learners notice the target learning details (i.e. collocations) in the fields of distracting items. To put it more simply, teachers should explicitly call these learners' attention to the co-occurrence of words in target collocations and highlight their significance in enhancing L2 fluency and accuracy. Then, they should provide FDs with a plan to maintain their direction towards the learning goal (i.e. collocation acquisition). To achieve this aim, FD learners should be taught the efficient ways of organizing and storing these chunks in their working memory in order to be able to retrieve the stored collocations more efficiently from their long-term memory. Hence, it is recommended that teachers promote restructuring abilities in FD learners in order to help them to be more organized in storing target collocations in their working memory. In other words, FDs should be taught to activate their L2 prior knowledge in order to link new collocations with their prior related information. This causes the new collocations fit well into their prior related knowledge in working memory. Such organized storage leads to better recall and retention. Such direct teaching of the required strategies can help FD learners to rectify their deficiencies in the process of L2 learning, in general, and collocation learning, in particular.

Furthermore, language learners should learn about their own FD/FI tendencies. Indeed, being aware of the characteristics of FD/FI learners and knowing where they fall on this spectrum can encourage them to develop their natural strengths and overcome their weaknesses. It is therefore recommended that teachers inform FD and FI learners of their particular tendencies and styles and teach them the strategies that are appropriate for those styles. Indeed, such self-awareness help them adopt suitable learning strategies, causing them to be more successful in processing information in a learning task.

The findings of the present research regarding the input-flood technique, however, cannot be generalized to other implicit input enhancement techniques since, to the best of the present researcher's knowledge, no researchers have examined their effectiveness with regard to learners' FD/FI cognitive styles. Hence, the only conclusion that can be drawn from the results of the current research is that input-flooding or high frequency exposure alone is not an appropriate method for teaching collocations as it is not equally beneficial for all learners with different FD/FI tendencies. Since it is not practical to separate FDs from FIs in L2 classrooms, teachers are recommended employing collocation teaching approaches that are suitable for both types. Finding such methods, however, requires further research in this area.

Nonetheless, generalization of the findings of the current research should be made with extreme caution since much more research with larger sample size is needed. This study was limited to only one level of proficiency, i.e. intermediate. Future research, with larger groups, can include L2 learners of higher or lower levels of language proficiency to examine whether FD and FI learners' levels of language proficiency can affect the way they process information. Moreover, the impacts of factors other than FD/FI cognitive style, for example other cognitive styles, sex and age of learners, need to be considered. Another limitation is that only one of the input-enhancement techniques, i.e. input-flood treatment, was employed in this research study. The effectiveness of other input-enhancement techniques, such as visual enhancement, can be explored in other experiments. In addition, examining FD and FI learners' processing behaviour in learning tasks using more explicit instructional methods or the combination of explicit and implicit techniques in relation to collocations may yeild different 
Hamed Mahvelati, E.

results. Finally, the qualitative data of the present study were collected through semi-structured interviews, retrospective-reflective tasks as well as tests of intake. Other qualitative data collection techniques such as journal writing, classroom observation, etc. can be used to probe into the issue in more depth.

\section{References}

Abraham, R. G. (1985). Field independence/dependence and the teaching of grammar. TESOL Quarterly, 19,689-702. http://dx.doi.org/10.2307/3586671

Adegoke, B. A. (2011). Effect of indirect teacher influence on dependent-prone students' learning outcomes in secondary school mathematics. Electronic Journal of Research in Educational Psychology, 9(1), 283-308. https://doi.org/10.25115/ejrep.v9i23.1438

Akbari, R., Jafar, S. R., \& Asadi, A. (2006). Who can guess better? The relationship between word class and learners' style. Teaching English Language and Literature Society of Iran, 1(1), 1-23.

Alloway, T. P., Banner, G. E., \& Smith, P. (2010). Working memory and cognitive styles in adolescents' attainment. British Journal of Educational Psychology, 80(4), 567-581. https://doi.org/10.1348/000709910X494566

Alloway, T. P., Gathercole, S. E., Kirkwood, H., \& Elliott, J. (2009). The working memory rating scale: A classroom-based behavioral assessment of working memory. Learning and Individual Differences, 19(2), 242-245. https://doi.org/10.1016/j.lindif.2008.10.003

Altun, A., \& Cakan, M. (2006). Undergraduate students' academic achievement, field dependent/independent cognitive styles and attitude toward computers. Educational Technology \& Society, 9(1), 289-297.

Angeli, C. (2013). Examining the effects of field dependence-independence on learners' problem-solving performance and interaction with a computer modeling tool: Implications for the design of joint cognitive systems. Computers \& Education, 62, 221-230. https://doi.org/10.1016/j.compedu.2012.11.002

Ary, D., Jacobs, L. C., Sorensen, C., \& Razavieh, A. (2010). Introduction to research in education. Belmont, CA: Cengage Learning.

Atkinson, R. C., \& Shiffrin, R. M. (1968). Human memory: A proposed system and its control processes. Psychology of Learning and Motivation, 2, 89-195. https://doi.org/10.1016/S0079-7421(08)60422-3

Bachman, L. F. (1990). Fundamental considerations in language testing. Oxford: Oxford University Press.

Barron. (2004). How to prepare for the TOEFL. New York: Barron's Educational Series, Inc.

Cao, Y. (2006). Effects of field dependent-independent cognitive styles and cueing strategies on students' recall and comprehension (Doctoral dissertation). Retrieved from https://vtechworks.lib.vt.edu/bitstream/handle/10919/29017/CCdissertation_FinalVersion_REV.pdf?seq $\underline{\text { uence }=1}$

Carter, E. F. (1988). The relationship of field dependent/independent cognitive style to Spanish language achievement and proficiency: A preliminary report.The Modern Language Journal, 72(1), 21-30. https://doi.org/10.1111/j.1540-4781.1988.tb04163.x

Cassidy, S. (2004). Learning styles: An overview of theories, models, and measures. Educational Psychology, 24(4), 419-444. https://doi.org/10.1080/0144341042000228834

Chapelle, C. A., \& Heift, T. (2009). Individual learner differences in CALL: The field-idependence/dependence (FID) construct. CALICO Journal, 26(2), 246-266. https://doi.org/10.1558/cj.v26i2.246-266

Chapelle, C., \& Roberts, C. (1986). Ambiguity tolerance and field independence as predictors of proficiency in English as a second language. Language learning, 36(1), 27-45. https://doi.org/10.1111/j.1467-1770.1986.tb00367.x

Chen, S. Y., \& Macredie, R. D. (2002). Cognitive styles and hypermedia navigation: Development of a learning model. Journal of the American society for information science and technology, 53(1), 3-15. https://doi.org/10.1002/asi.10023

Corno, L. (2008). On teaching adaptively. Educational Psychologist, 43, 161-173. https://doi.org/10.1080/00461520802178466 
Field-dependent/independent cognitive style preferences of EFL learners in an implicit learning task

Craik, F. I. M., \& Lockhart, R. S. (1972). Levels of processing: A framework for memory research. Journal of Verbal Learning and Verbal Behaviour, 11, 671-684. https://doi.org/10.1016/s0022-5371(72)80001-x

Creswell, J. W. (2007). Qualitative inquiry and research design ( $2^{\text {nd }}$ ed.). Thousand Oaks, CA: Sage.

Creswell, J. W. (2008). Educational research: Planning, conducting, and evaluating quantitative and qualitative research. Upper Saddle River, New Jersey.

Dabaghi, A., \& Goharimehr, N. (2011). The relationship between learning styles of field-dependence/independence and integrative/discrete point methods of grammar teaching. World Journal of English Language, 1(2), 79-89. https://doi.org/10.5430/wjel.v1n2p79

Daniels, H. L. (1996). Interaction of cognitive style and learner control of presentation mode in a hypermedia environment (Doctoral dissertation). Retrieved from https://vtechworks.lib.vt.edu/handle/10919/30394

Davis, J. K. (1991). Educational implications of field dependence-independence. In S. Wapner \& J. Demick (Eds.), Field dependence-independence: Cognitive style across the life span (pp. 149-175). Hillsdale, NJ, US: Lawrence Erlbaum Associates, Inc.

Davis, J. K., \& Cochran, K. F. (1982). Toward an information processing analysis of field-independence. Paper presented at the annual meeting of the American Educational Research Association, New York.

Davis, J. K. \& Cochran, K. F. (1989). An information processing view of field dependence-independence. Early Child Development and Care, 43, 129-145. https://doi.org/10.1080/0300443890430110

Dawson-Brew, E. (2010). The relative effect of field dependent and field independent learning styles on the academic performance of undergraduate students of the university of Cape Coast, Ghana. Retrieved from http://www.faqs.org/periodicals/201009/2087472301.html

Driscoll, M. P. (2000). Psychology of learning for instruction ( $2^{\text {nd }}$ ed.). Needham Heights, MA: Allyn \& Bacon.

Durso, F. T., Reardon, R., \& Jolly, E. J. (1985). Self-nonself-segregation and reality monitoring. Journal of Personality and Social Psychology, 48(2), 447-455. https://doi.org/10.1037/0022-3514.48.2.447

Durrant, P., \& Schmitt, N. (2010). Adult learners' retention of collocations from exposure. Second Language Research, 26(2), 163-188. https://doi.org/10.1177/0267658309349431

Dyer, J. E., \& Observe, E. W. (1996). Effects of teaching approach on achievementof agricultural education students with varying learning style. Journal of Agricultural Education, 3, 43-51.

http://dx.doi.org/10.5032/jae.1996.03043

Ellis, R. (2001). Introduction: Investigating form-focused instruction. Language Learning, 51(1), 1-46. https://doi.org/10.1111/j.1467-1770.2001.tb00013.x

Ghonsooly, B., \& Eghtesadee, A. R. (2006). Role of cognitive style of field-dependence/independence in using metacognitive and cognitive reading strategies by a group of skilled and novice Iranian students of English literature.The Asian EFL Journal, 8(4), 119-150.

Goodenough, D. R. (1976). The role of individual differences in field dependence as a factor in learning and memory. Psychological Bulletin, 83(4), 675-694. https://doi.org/10.1037//0033-2909.83.4.675

Gredler, M. E. (2001). Learning and instruction: Theory into practice $\left(4^{\text {th }}\right.$ ed.). Upper Sadle River, NJ: Merrill Prentice Hall.

Griffiths, R., \& Sheen, R. (1992). Disembedded figures in the landscape: a reappraisal of L2 research on field dependence/independence. Applied Linguistics, 13, 133-148. http://dx.doi.org/10.1093/applin/13.2.133.

Guisande, M. A., Páramo, M. F., Tinajero, C., \& Almeida, L. S. (2007). Field dependence-independence (FDI) cognitive style: An analysis of attentional functioning. Psicothema, 19(4), 572-577.

Hansen, J., \& Stansfield, C. (1981). The Relationship of field dependent-independent cognitive styles to foreign language achievement. Language learning, 31(2), 349-367. https://doi.org/10.1111/j.1467-1770.1981.tb01389.x

Hashemian, M., \& Farhang-Ju, M. (2018). Effects of metalinguistic feedback on grammatical accuracy of Iranian field (in) dependent L2 learners' writing ability. Research in Applied Linguistics, 9(2), 141-161. https://doi.org/10.22055/rals.2018.13797

Hatch, E., \& Farhady, H. (1981). Research design and statistics for applied linguistics. Rowley, MA: Newburry. Hernández, T. A. (2011). Re-examining the role of explicit instruction and input flood on the acquisition of Spanish discourse markers. Language Teaching Research, 15(2), 159-182. 
Hamed Mahvelati, E.

https://doi.org/10.1177/1362168810388694

Hill, J. (2000). Revising priorities: From grammatical failure to collocational success. In M. Lewis (Ed.), Teaching collocations: Further developments in the lexical approach (pp. 47-69). Hove: Language Teaching Publications.

Hoey, M. (2012). Lexical priming: A new theory of words and language. Routledge. https://doi.org/10.4324/9780203327630

Huang, J., \& Chao, L. (2000). Field dependence versus field independence of students with and without learning disabilities. Perceptual and Motor Skills, 90(1), 343-346. https://doi.org/10.2466/pms.2000.90.1.343

Jonassen, D. H., \& Grabowski, B. (1993). Individual differences and instruction.New York: Allen \& Bacon.

Jones, S. (1993). Cognitive learning styles: Does awareness help? A review of selected literature. Language awareness, 2(4), 195-207. https://doi.org/10.1080/09658416.1993.9959834

Koya, T. (2003). A study of collocation in English and Japanese noun-verb combinations. Intercultural communication studies, 12(1), 125-141.

Krueger, R. A. (1994). Focus groups: A practical guide for applied research. Thousand Oaks, CA: Sage Publications.

Lang, A. (1995). Defining audio/video redundancy from a limited-capacity information processing perspective. Communication Research, 22(1), 86-115. https://doi.org/10.1177/009365095022001004

Laufer, B., \& Waldman, T. (2011). Verb-noun collocations in second language writing: A corpus analysis of learners' English. Language Learning, 61(2), 647-672. https://doi.org/10.1111/j.1467-9922.2010.00621.x

Lewis, M. (1993). The lexical approach. Hove: Language Teaching Publications.

Lewis, M. (2000). Language in the lexical approach. In M. Lewis (Ed.), Teaching collocation: Further developments in the lexical approach (pp. 155-184). London: Language Teaching Publications.

Liu, M., \& Reed, W. M. (1995). The relationship between the learning strategies and learning styles in a hypermedia environment. Computers in human behaviour, 10(4), 419-434. https://doi.org/10.1016/0747-5632(94)90038-8

McMillan, J. H., \& Schumacher, S. (2010). Research in education: Evidence-based inquiry (7th ed.). US: Pearson Education.

Mahdavian, A., \& Kormi-Nouri, R. (2008). Effects of attention and levels of processing on explicit and implicit memory function with interesting and unteresting tasks in university students. Journal of Applied Sciences, 8(6), 1055-1060. https://doi.org/10.3923/jas.2008.1055.1060

Mancy, R., \& Reid, N. (2004). Aspects of cognitive style and programming. In Proceedings of the Sixteenth Annual Workshop of the Psychology of Programming Interest Group (pp. 1-9). Carlow, Ireland: Institute of Technology.

Messick, S. (1970). The criterion problem in the evaluation of instruction: assessing possible, not just intended outcomes, In M. C. Wittock \& D. E. Wiley (Eds.), The evaluation of instruction: issues and problems (pp. 183-220). New York: Holt, Rinehart and Winston.

Mirzapour, M., \& Barjesteh, H. (2017). The efficacy of audio input flooding tasks on learning grammar: uptake of present tense. Language and Translation, 7(3), 25-34.

Muhammad, T., Daniel, E. G. S., \& Abdurauf, R. A. (2015). Cognitive styles field dependence/independence and scientific achievement of male and female students of Zamfara state college of education Maru, Nigeria. Journal of Education and Practice, 6(10), 58-63.

Nesselhaulf, N. (2003). The use of collocations by advanced learners of English and some implications for teaching. Applied Linguistics, 24(2), 223-242. http://dx.doi.org/10.1093/applin/24.2.223

Niroomand, S. M., \& Rostampour, M. (2014). The impact of field dependence/independence cognitive styles and gender differences on lexical knowledge: The case of Iranian academic EFL learners. Theory and Practice in Language Studies, 4(10), 2173-2179. https://doi.org/10.4304/tpls.4.10.2173-2179

Nozari, A. Y., \& Siamian, H. (2015). The relationship between field dependent-independent cognitive style and understanding of English text reading and academic success. Materia Socio-Medica, 27(1), 39-41. https://doi.org/10.5455/msm.2014.27.39-41 
Field-dependent/independent cognitive style preferences of EFL learners in an implicit learning task

Öztina, S. (2009). Effects of input flood and negative evidence on learning of make/do collocations: A study with seventh grade Turkish EFL students (Doctoral dissertation). Anadolu University Institute of Educational Sciences, Eskisehir, Turkey.

Pierce, J. W. (1980). Field independence and imagery-assisted prose recall of children. Journal of Educational Psychology, 72(2), 200-203. http://dx.doi.org/10.1037/0022-0663.72.2.200

Pithers, R. T. (2002). Cognitive Learning Style: A review of the field dependent-field independent approach. Journal of Vocational Education \& Training, 54(1), 117-32. https://doi.org/10.1080/13636820200200191

Pulido, D. (2004). The relationship between text comprehension and second language incidental vocabulary acquisition: A matter of topic familiarity?.Language Learning, 54(3), 469-523. https://doi.org/10.1111/j.1467-9922.2007.00415.x

Rajagopalan, J., Modi, S., Kumar, P., Khushu, S., \& Mandal, M. K. (2015). Differential neural activation for camouflage detection task in field-independent and field-dependent individuals: Evidence from fMRI. Journal of biosciences, 40(5), 909-919. https://doi.org/10.1007/s12038-015-9568-7

Rankin, J. M. (1988). Designing thinking-aloud studies in ESL reading. Reading in a Foreign Language, 4(2), 119-132.

Riding, R. J., Grimley, M., Dahraei, H., \& Banner, G. (2003). Cognitive style, working memory and learning behaviour and attainment in school subjects. British Journal of Educational Psychology, 73(2), 149-169. https://doi.org/10.1348/00070990360626912

Rittschof, K. A. (2010). Field dependence-independence as visuospatial and executive functioning in working memory: Implications for instructional systems design and research. Educational Technology Research and Development, 58(1), 99-114. https://doi.org/10.1007/s11423-008-9093-6

Scardamalia, M. (1977). Information processing capacity and the problem of horizontal decalage: A demonstration using combinatorial reasoning tasks. Child Development, 48(1), 28-37. https://doi.org/10.2307/1128877

Saracho, O. (2003). Matching teachers' and students' cognitive styles. Early Child Development and Care, 173(2-3), 161-173. https://doi.org/10.1080/03004430303097

Schmidt, R. (1990). The role of consciousness in second language learning. Applied Linguistics, 11, 129-158. http://dx.doi.org/10.1093/applin/11.2.129

Shan, L., \& Niannian, Z. (2006). The influence of cognitive style and reading strategies on English reading: an empirical study. CELEA Journal, 29(3), 56-63.

Shokouhi, H., \& Mirsalari, G. A. (2010). Collocational knowledge versus general linguistic knowledge among Iranian EFL learners. TESL-EJ 13(4). Retrieved from http://www.tesl-ej.org/wordpress/issues/volume13/ej52/ej52a7/

Sözcü, Ö. F., İpek, İ., \& Kinay, H. (2016). The attitudes of field dependence learners for Learner Interface Design (LID) in e-learning instruction. Universal Journal of Educational Research, 4(3), 539-546. https://doi.org/10.13189/ujer.2016.040310

Spiro, R. J., \& Tirre, W. C. (1980). Individual differences in schema utilization during discourse processing. Journal of Educational Psychology, 72(2), 204-208. https://doi.org/10.1037//0022-0663.72.2.204

Stansfield, C., \& Hansen, J. (1983). Field dependence-independence as a variable in second language cloze test performance. TESOL Quarterly, 17(1), 29-38. https://doi.org/10.2307/3586422

Szudarski, P., \& Carter, R. (2016). The role of input flood and input enhancement in EFL learners' acquisition of collocations. International Journal of Applied Linguistics, 26(2), 245-265. https://doi.org/10.1111/ijal.12092

Tinajero, C., \& Páramo, M. F. (1997). Field dependence-independence and academic achievement: a reexamination of their relationship. British Journal of Educational Psychology, 67(2), 199-212. https://doi.org/10.1111/j.2044-8279.1997.tb01237.x

Tinajero, C., \& Paramo, M. F. (1998). Field dependence-independence cognitive style and academic achievement: A review of research and theory. European Journal of Psychology of Education, 13(2), 227-251. https://doi.org/10.1007/bf03173091 
Hamed Mahvelati, E.

Tinajero, C., Castelo, A., Guisande, A., \& Páramo, F. (2011). Adaptive teaching and field dependence-independence: Instructional implications. Revista Latinoamericana de Psicología, 43(3), 497-510.

Tinajero, C., Lemos, S. M., Araújo, M., Ferraces, M. J., \& Páramo, M. F. (2012). Cognitive style and learning strategies as factors which affect academic achievement of Brazilian university students. Psicologia: Reflexão e Crítica, 25(1), 105-113.

Zhang, L. F. \& Sternberg, R. J. (2006). The nature of intellectual styles. Mahwah, New Jersey, NJ: Lawrence Erlbaum Associates.

Zhou, J., Zhou, C., Li, J., \& Zhang, M. (2015). Cognitive style modulates conscious but not unconscious thought: Comparing the deliberation-without-attention effect in analytics and wholists. Consciousness and cognition, 36, 54-60. https://doi.org/10.1016/j.concog.2015.05.018

Wang, P. (2012). Teaching and learning English verb tenses in a Taiwanese university. English Linguistics Research, 1(1), 18-34. https://doi.org/10.5430/elr.v1n1p18

Wapner, S., \& Demick, J. (2014). Field dependence-independence: Bio-psycho-social factors across the life span. Psychology Press.

White, J. P. (2008). The effect of input-based instruction type on the acquisition of Spanish accusative critics. Electronic Theses, Treatises and Dissertations. Retrieved from http://diginole.lib.fsu.edu/etd

Witkin, H. A. (1962). Psychological differentiation:Studiea of development. New York:Wiley.

Witkin, H. A., Oltman, P. K., Raskin, E., \& Karp, S. A. (1971). A manual for the embedded figures test. Consulting Psychologist Press, Palo Alto, CA.

Witkin, H. A., \& Goodenough, D. R. (1981). Cognitive styles: Essence and origins. NY: International Universities Press.

Yousefi, M. (2011). Cognitive style and EFL learners' listening comprehension ability. Indonesian Journal of Applied Linguistics, 1(1), 73-83. https://doi.org/10.17509/ijal.v1i1.100 